\title{
Formulation and evaluation of bi-layer floating tablets of ziprasidone $\mathrm{HCl}$ and trihexyphenidyl $\mathrm{HCl}$
}

\author{
Sathis Kumar Dinakaran*, Santhos Kumar, David Banji, Harani Avasarala, Venkateshwar Rao
}

Nalanda College of Pharmacy, Nalgonda, Andhra Pradesh, India.

\begin{abstract}
The purpose of this research study was to establish ziprasidone $\mathrm{HCl} \mathrm{NR} 40 \mathrm{mg}$ and trihexyphenidyl $\mathrm{HCl} \mathrm{SR} \mathrm{4mg} \mathrm{in} \mathrm{the} \mathrm{form} \mathrm{of} \mathrm{bi-layer} \mathrm{sustained} \mathrm{release} \mathrm{floating} \mathrm{tablets.} \mathrm{The} \mathrm{tablets} \mathrm{were} \mathrm{prepared} \mathrm{using}$ sodium HPMC K4M / HPMC K15M as bio-adhesive polymers and sodium bicarbonate acting as a floating layer. Tablets were evaluated based on different parameters such as thickness, hardness, friability, weight variation, in vitro dissolution studies, content of active ingredient and IR studies. The physicochemical properties of the finished product complied with the specifications. In vitro release from the formulation was studied as per the USP XXIII dissolution procedure. The formulations gave a normal release effect followed by sustained release for $12 \mathrm{~h}$ which indicates bimodal release of ziprasidone $\mathrm{HCl}$ from the matrix tablets. The data obtained was fitted to Peppas models. Analysis of $\mathrm{n}$ values of the Korsmeyer equation indicated that the drug release involved non-diffusional mechanisms. By the present study, it can be concluded that bi-layer tablets of ziprasidone $\mathrm{HCl}$ and trihexyphenidyl $\mathrm{HCl}$ will be a useful strategy for extending the metabolism and improving the bioavailability of Ziprasidone $\mathrm{HCl}$ and Trihexyphenidyl $\mathrm{HCl}$.
\end{abstract}

Uniterms: Bi-layer tablet. Ziprasidone HCl. Trihexyphenidyl HCl. Sustained release.

O propósito deste trabalho foi preparar ziprasidona. $\mathrm{HCl} \mathrm{NR} 40 \mathrm{mg}$ e triexifenidila.HCl SR $4 \mathrm{mg}$ na forma de comprimidos efervescentes bicamada de liberação controlada. Os comprimidos foram preparados utilizando HPMC K4M / HPMC K15M sódico como polímero bioadesivo e bicarbonato como camada efervescente. Os comprimidos foram avaliados quanto a diferentes parâmetros, como espessura, dureza, friabilidade, variação de peso, dissolução in vitro, conteúdo do ingrediente ativo e estudos de IV. As propriedades físico-químicas dos produtos finais cumprem as especificações. A liberação in vitro da formulação foi estudada de acordo com o procedimento de dissolução da USP XXIII. As formulações resultaram em liberação normal, seguida por liberação controlada por 12 h, o que indica a liberação bimodal de cloridrato de ziprasidona dos comprimidos matriz. Os dados obtidos se adequaram aos modelos de Peppas. A análise de valores de $\mathrm{n}$ da equação de Korsmeyer indicou que a liberação do fármaco envolveu mecanismos não difusionais. Por este estudo, pode-se concluir que os comprimidos bicamada de ziprasidona. $\mathrm{HCl}$ e de triexifenidila. $\mathrm{HCl}$ serão um bom caminho para estender o metabolismo e para melhorar a biodisponibilidade de ziprasidona. $\mathrm{HCl}$ e de triexifenidila. $\mathrm{HCl}$.

Unitermos: Comprimidos bicamada. Ziprasidona.HCl. Triexifenidila.HCl. Liberação controlada.

\section{INTRODUCTION}

Combination therapy has various advantages over monotherapy such as minimization of dose-dependent side effects, a low-dose combination of two different agents can reduce the dose-related risk, the addition of one agent may counteract some deleterious effects of the other, while using

\footnotetext{
*Correspondence: Sathis Kumar Dinakaran. Nalanda College of Pharmacy,
} Nalgonda, Andhra Pradesh, India. E-mail: satmpdina@yahoo.co.in low dosage of two different agents minimizes the clinical and metabolic effects that occur with maximal dosage of individual components of the combined tablet. Ziprasidone is a one of the potent psychotropic agents that is chemically unrelated to phenothiazine or butyrophenone antipsychotic agents. Ziprasidone is indicated for the treatment of schizophrenia, bipolar I disorder and acute agitation in schizophrenic patients (www.rxlist.com). Ziprasidone is well absorbed after oral administration, reaching peak plasma concentrations in 6 to 8 hours. The absolute bioavailabi- 
lity of a $20 \mathrm{mg}$ dose is approximately $60 \%$. Studies show that the incidence of reported extra pyramidal side effects (which includes the adverse reactions of extrapyramidal syndrome, hypertonia, dystonia, dyskinesia, hypokinesia, tremor, paralysis and twitching) for ziprasidone-treated patients in short-term, placebo-controlled schizophrenia trials was $14 \%$ vs. $8 \%$ for placebo, and the incidence of reported extra pyramidal side effects (EPS) (www.thomsonhc.com) for ziprasidone-treated patients in short-term, placebo-controlled bipolar disorder trials was $31 \%$ vs. $12 \%$ for placebo (Sean et al., 2006) . Thus, there is a need of a drug for the treatment of EPS while ziprasidone therapy continues being administered. Trihexyphenidyl hydrochloride is a synthetic antispasmodic drug indicated as an adjunct in the treatment of all forms of Parkinsonism (post-encephalitic, arteriosclerotic, and idiopathic). Additionally, it is indicated for the control of extrapyramidal disorders caused by central nervous system drugs (www. rxlist.com) such as the dibenzoxazepines, phenothiazines, thioxanthenes, and butyrophenones (Anthony et al., 2006). The dosage of trihexyphenidyl hydrochloride associated to EPS is usually 5 to $15 \mathrm{mg}$ daily in 2 or 3 divided doses. Some patients, however, are successfully treated with as little as 1 $\mathrm{mg}$ daily. However, high doses of trihexyphenidyl $\mathrm{HCl}$ may produce central nervous system manifestations and signs that mimic functional psychosis such as hallucinations, delusions, agitation, anxiety and paranoia (Porteus et al., 1956). A common practice when prescribing anti-psychotics is the concurrent administration of anticholinergics, either to prevent or treat EPS. This addition of anticholinergics to patients on antipsychotics, particularly, those with significant inherent anticholinergic properties, would theoretically increase the risk of anticholinergic side-effects. One of the side-effects that is rarely recognized or reported is exacerbation of the positive symptoms of schizophrenia, which if unrecognized, may cloud the physician's judgment on the patient's progress (Owens et al., 1999). Combination therapy of antipsychotics along with Trihexyphenidyl.HCl is important for the adequate control of extrapyramidal side effects. Hence, to reduce frequency of administration and to improve patient compliance, bilayer tablet formulations having a normal disintegration layer (of ziprasidone. $\mathrm{HCl}$ ) and another of a sustained floating release layer (of trihexyphenidyl. $\mathrm{HCl}$ ) was attempted. The multilayered tablet concept has been long utilized to develop sustained release formulations. These tablets have a fast releasing layer and may contain bi- or triple layers to sustain the drug release (Abraham et al., 1997). The pharmacokinetic advantage relies on the fact that drug release from normal releasing granules leads to a rise in blood concentration. However, the blood level is maintained at a steady state as the drug is released from the sustaining granules. Among the different polymers, HPMC K4M, HPMC K15M have been used successfully to obtain appropriate sustained release matrix formulations of different materials (Velasco et al., 1999). The aim of the present study was to formulate bilayered tablets of trihexyphenidyl.HCl SR and ziprasidone. $\mathrm{HCl}$ with a normal release layer.

\section{EXPERIMENTAL}

\section{Materials}

Ziprasidone hydrochloride (99.96\% purity), HPMC K4M, HPMC K15M and microcrystalline cellulose were from AET pharmaceuticals, Hyderabad. Trihexyphenidyl hydrochloride (99.96\% purity) was given by Pharmafabricon, Madurai as a gift sample. Sodium bicarbonate [Finer chemicals (India) pvt.ltd. Ahmedabad], colloidal silicon dioxide [Accord labs. Secunderabad], starch [Karnataka fine chem. Bangalore], magnesium stearate and talc [S.D fine chem.ltd] were sourced from the local market. All other reagents and chemicals used were of analytical reagent grade.

Development of bilayer tablet of trihexyphenidyl. $\mathrm{HCl}$ and ziprasidone. $\mathrm{HCl}$ was carried out by the direct compression method. Finally it was optimized according to several evaluation parameters.

\section{Dose calculation for sustained release layer}

The total dose of trihexyphenidyl for a once-daily sustained-release formulation was calculated by the following equation

$D_{t}=$ Dose $\left(1+0.693 \times t / t_{1 / 2}\right)$

Where, $D_{t}=$ total dose of drug; Dose $=$ dose of the immediate release part; $t=$ time (hours) during which the sustained release is desired; $t_{1 / 2}=$ half-life of the drug.

For the normal release layer, the drug dose was selected based on the drug profile.

\section{Construction of theoretical release profile}

The theoretical release profile of a drug for the sustained release layer was plotted on the basis of the loading dose and the drug availability rate.

\section{Physical characteristic (color) studies for drug-excipients}

Preformulation testing entailed an investigation of physical and chemical properties of drug substances alone and when combined with excipients. It was the first step in the rational development of the dosage form. Trihexyphe- 
nidyl. $\mathrm{HCl}$ and ziprasidone. $\mathrm{HCl}$ alone and mixtures consisting of trihexyphenidyl. $\mathrm{HCl}$ with various excipients, and ziprasidone. $\mathrm{HCl}$ with various excipients at a 1:5 ratio were produced and kept at room temperature in a glass vial. This was carried out for one month in open and closed glass vials. At 2 and 4 week intervals, the samples were withdrawn and physical characteristics such as color change, if any, was recorded. Finally, the mixture with no color change was selected for formulation (Vijay et al., 2002).

\section{Preparation of bilayer formulation}

- Preparation of normal release layer of ziprasidone. $\mathrm{HCl}$ : The immediate release layer of ziprasidone. $\mathrm{HCl}(\mathrm{Zl}$ and Z2) was prepared by the direct compression method as per the composition Table I. Ziprasidone HCl, microcrystalline cellulose and starch were passed through sieve 40. All the above were mixed in geometric proportion in a poly bag for 15 minutes. Aerosil and magnesium stearate were passed through sieve 60 and mixed with above blend in a poly bag for 2 minutes.

- Preparation of sustained release layer of trihexyphenidyl. $\mathrm{HCl}$ :

The dose of trihexyphenidyl. $\mathrm{HCl}$ for sustained release was set at $4 \mathrm{mg}$ using the dose calculation formula.
The trihexyphenidyl.HCl (T1 to T10) sustained release layer was prepared by the direct compression technique with various excipients as per the formula given in Table II. The drug and additives were passed through sieve 40 and mixed thoroughly in a poly bag for 30 minutes for uniform mixing. Dried mixture materials were passed through a milling $1.5 \mathrm{~mm}$ screen and sifted through sieve 20 and finally lubricated with the lubricants.

- Characterization of granules:

Prior to compression, granules were evaluated for their characteristic parameters, such as density, bulk density, tapped density, compressibility index and Hausner Ratio. Carr's compressibility index was calculated from the bulk and tapped densities using a digital tap density apparatus (Electrolab Ltd, India).

- Preparation of bilayer formulation:

Final bilayer tablets were compressed as one layer only for trihexyphenidyl. $\mathrm{HCl}$ and with a second layer for ziprasidone.HCl using a $19.8 \times 8.7 \mathrm{~mm}$ oblong shaped punch on a 27 station tablet compression machine (Cadmach, India) in the following manner F1(T1+Z1), F2(T2+Z1), F3(T3+Z1), F4(T4+Z1), F5(T5+Z1), F6(T6+Z1), F7(T7+Z1), F8(T8+Z1), F9(T9+Z1), F10(T10+Z1), F11(T1+Z2), F12(T2+Z2), F13(T3+Z2), F14(T4+Z2),

TABLE I - Preparation of normal release layer of ziprasidone.HCl

\begin{tabular}{lcccc}
\hline S. No & Ingredient & Category & (Z1) Quantity/Tablet (in mg) & (Z2) Quantity/Tablet (in mg) \\
\hline 1 & Ziprasidone. $\mathrm{HCl}$ & Active ingredient & 40 & 40 \\
2. & Microcrystalline cellulose & Binder/diluent & 52 & 47 \\
3. & Aerosil & Glidant & 5 & 10 \\
4. & Colloidal Silicon dioxide & Adsorbent/ tablet disintegrant & 2 & 2 \\
5 & Magnesium stearate & Lubricant & 1 & 1 \\
& Total composition & & $100 \mathrm{mg} / \mathrm{tablet}$ & $100 \mathrm{mg} / \mathrm{tablet}$ \\
\hline
\end{tabular}

TABLE II - Preparation of sustained release layer of trihexyphenidyl.HCl

\begin{tabular}{|c|c|c|c|c|c|c|c|c|c|c|c|c|}
\hline \multirow[t]{2}{*}{ S.No. } & \multirow[t]{2}{*}{ Ingredient } & \multirow[t]{2}{*}{ Category } & \multicolumn{10}{|c|}{ Quantity/Tablet (in mg) } \\
\hline & & & $\mathrm{T} 1$ & $\mathrm{~T} 2$ & $\mathrm{~T} 3$ & $\mathrm{~T} 4$ & T5 & $\mathrm{T} 6$ & $\mathrm{~T} 7$ & $\mathrm{~T} 8$ & T9 & $\mathrm{T} 10$ \\
\hline$\overline{1 .}$ & Trihexyphenidyl.HCl & Active ingredient & 4 & 4 & 4 & 4 & 4 & 4 & 4 & 4 & 4 & 4 \\
\hline 2. & HPMC K15M & Polymer & 40 & 35 & 30 & 25 & 20 & - & - & - & - & - \\
\hline 3. & HPMC K4M & Polymer & - & - & - & - & - & 40 & 35 & 30 & 25 & 20 \\
\hline 4. & Starch & Binder & 1.5 & 1.5 & 1.5 & 1.5 & 1.5 & 1.5 & 1.5 & 1.5 & 1.5 & 1.5 \\
\hline 5. & \multicolumn{2}{|c|}{ Talc Glidant } & 1 & 1 & 1 & 1 & 1 & 1 & 1 & 1 & 1 & 1 \\
\hline \multirow[t]{2}{*}{6.} & Sodium bicarbonate & Effervescent Material & 3.5 & 8.5 & 13.5 & 18.5 & 23.5 & 3.5 & 8.5 & 13.5 & 18.5 & 23.5 \\
\hline & \multicolumn{2}{|c|}{ Average Weight of tablets (mg/tablet) } & 50 & 50 & 50 & 50 & 50 & 50 & 50 & 50 & 50 & 50 \\
\hline
\end{tabular}


F15(T5+Z2), F16(T6+Z2), F17(T7+Z2), F18(T8+Z2), F19(T9+Z2) and F20(T10+Z2). The tablet was compressed as a bilayer tablet using both Trihexyphenidyl $\mathrm{HCl}$ and Ziprasidone $\mathrm{HCl}$ granules. To achieve this, Trihexyphenidyl $\mathrm{HCl}$ granules were introduced first into the die cavity and a slight pre compression was made so that the layer was uniformly distributed. Subsequently, ziprasidone. $\mathrm{HCl}$ granules were added and a final compression was made.

- Physical tests for bilayer tablets:

Standard physical tests for the bilayer tablets were performed and average values calculated. Mass variation was determined by weighing 20 tablets individually, and the average mass and percent variation of each tablet was calculated. Hardness was determined by taking 6 tablets from each formulation using a Monsanto hardness tester (Electrolab Pvt. Ltd., India) and the average pressure $\left(\mathrm{kg} \mathrm{cm}^{-2}\right)$ applied to crush the tablet was determined. Friability was determined by first weighing 20 tablets after dusting and then placing them in a Roche Friabilator, which was rotated for $4 \mathrm{~min}$ at $25 \mathrm{rpm}$. After dusting, the total remaining mass of the tablets was recorded and the percent friability calculated. Thickness was determined by Digital Vernier Calipers and expressed in $\mathrm{mm}$. (Leon Lachmann, et al., 1987)

\section{Drug content uniformity}

- Determination of drug content of Ziprasidone $\mathrm{HCl}$ :

The standard ziprasidone. $\mathrm{HCl}(10 \mu \mathrm{g} / \mathrm{mL})$ was prepared using $7.4 \mathrm{pH}$ phosphate buffer with $1 \%$ sodium lauryl sulphate (SLS). Ten tablets with predetermined weight from each batch were taken and crushed in a mortar. An amount equivalent to $100 \mathrm{mg}$ was weighed and transferred to a $100 \mathrm{~mL}$ volumetric flask and $7.4 \mathrm{pH}$ phosphate buffer with $1 \%$ SLS was sonicated for about $20 \mathrm{~min}$ to ensure complete solubility of the drug. The mixture was made up to volume using $7.4 \mathrm{pH}$ phosphate buffer with $1 \% \mathrm{SLS}$. The solution was suitably diluted and finally $10 \mu \mathrm{g} / \mathrm{mL}$ concentrated solutions were prepared. Absorption was determined by a UV-Visible spectrophotometer at $316 \mathrm{~nm}$ for both standard and sample solutions. The content of ziprasidone. $\mathrm{HCl}$ per tablet in $\mathrm{mg}$ was then calculated.

- Determination of drug content of trihexyphenidyl.HCl:

The standard trihexyphenidyl.HCl $(10 \mu \mathrm{g} / \mathrm{mL})$ was prepared using $0.1 \mathrm{~N}$ hydrochloric acid. Ten tablets with predetermined weight from each batch were taken and crushed in a mortar. An amount equivalent to $100 \mathrm{mg}$ was weighed and transferred to a $100 \mathrm{~mL}$ volumetric flask and $0.1 \mathrm{~N}$ hydrochloric acid was sonicated for about $20 \mathrm{~min}$ to ensure complete solubility of the drug. The mixture was made up to volume using $0.1 \mathrm{~N}$ hydrochloric acid. The solution was suitably diluted and finally $10 \mu \mathrm{g} / \mathrm{mL}$ concentrated solutions were prepared. The absorption was determined by a UV-Visible spectrophotometer at $250 \mathrm{~nm}$ for both standard and sample solutions. The content of trihexyphenidyl $\mathrm{HCl}$ per tablet in $\mathrm{mg}$ was then calculated.

\section{In vitro dissolution}

- Preparation of stock solutions:

From $100 \mu \mathrm{g} / \mathrm{mL}$ stock ziprasidone. $\mathrm{HCl}$ solution, $2,4,6,8,10,12,14,16$, and $18 \mu \mathrm{g} / \mathrm{mL}$ solutions were prepared and absorbance measured at $316 \mathrm{~nm}$ using a UV spectrophotometer. Finally, a graph was plotted with concentration vs absorbance.

From $100 \mu \mathrm{g} / \mathrm{mL}$ stock trihexyphenidyl. $\mathrm{HCl}$ solution, $2,4,6,8,10,12,14,16$, and $18 \mu \mathrm{g} / \mathrm{mL}$ solutions were prepared and absorbance measured at $250 \mathrm{~nm}$ using a UV spectrophotometer. Finally, a graph was plotted with concentration vs absorbance.

- Procedure for ziprasidone. $\mathrm{HCl}$ tablets:

Release of ziprasidone. $\mathrm{HCl}$ was determined using a Dissolution Apparatus Type II of USP (Paddle) at 50 $\mathrm{rpm}$. The dissolution was studied using $900 \mathrm{~mL}$ of $7.4 \mathrm{pH}$ phosphate buffer solution with $1 \%$ SLS. The temperature was maintained at $37 \pm 0.5^{\circ} \mathrm{C}$. The sample $(5 \mathrm{~mL})$ was withdrawn at different time intervals, i.e., 5, 10, 15, 20, $25,30,35,40,45,50,55,60,75,90,105,120$ and 150 minutes, filtered through Whatman filter paper (Auroco Pvt Ltd, Thailand) and replaced by an equal volume of dissolution medium. Samples were suitably diluted and analyzed for ziprasidone. $\mathrm{HCl}$ content using spectrograms. The percentage of ziprasidone. $\mathrm{HCl}$ release was calculated. The solutions were analysed by using same procedure as the drug content assay.

- Procedure for trihexyphenidyl.HCl tablets:

Release of trihexyphenidyl.HCl was determined using a Dissolution Apparatus II of USP (Paddle) at 50 $\mathrm{rpm}$. The dissolution was studied using $500 \mathrm{~mL}$ of $0.1 \mathrm{~N}$ Hydrochloric acid. The temperature was maintained at $37 \pm 0.5^{\circ} \mathrm{C}$. Samples $(5 \mathrm{~mL})$ were withdrawn at different time intervals, i.e. 1, 2, 3, 4, 6, 8, 10 and 12 hours, filtered through Whatman filter paper (Auroco Pvt Ltd, Thailand) and replaced by an equal volume of dissolution medium. Samples were suitably diluted and analyzed for trihexyphenidyl. $\mathrm{HCl}$ content using spectrograms. The percentage of trihexyphenidyl. $\mathrm{HCl}$ release was calculated. 
- Dissolution profile comparison using dependent models: The experimental results of the release studies were fitted according to the exponential equation. Zero order release equation:

$\mathrm{Q}=\mathrm{K}_{0} \mathrm{t}$

Higuchi's square root of time equation:

$\mathrm{Q}=\mathrm{K}_{\mathrm{H}} \mathrm{t}^{1 / 2}$

Korsemeyer-Peppas equation:

$\mathrm{F}=\left(\mathrm{M}_{\mathrm{t}} / \mathrm{M}\right)=\mathrm{K}_{\mathrm{m}} \mathrm{t}^{\mathrm{n}}$

Where, $\mathrm{Q}=$ Amount of drug release at time $\mathrm{t}, \mathrm{M}_{\mathrm{t}}=$ drug release at time $t, M=$ total amount of drug in dosage form, $\mathrm{F}=$ fraction of drug release at time $\mathrm{t}, \mathrm{K}_{0}=$ zero order release rate constant, $\mathrm{K}_{\mathrm{H}}=$ Higuchi square root of time release rate constant, $\mathrm{K}_{\mathrm{m}}=$ constant dependent on geometry of dosage form, $\mathrm{n}=$ diffusion exponent indicating the mechanism of drug release where cylinder value of $n=0.55$ indicates Fickian diffusion, between 0.45 and 0.89 indicate anomalous transport and 0.89 indicates case-II transport.

Similarity factor (f2) was determined between theoretical profile value of trihexyphenidyl. $\mathrm{HCl}$ and selected formulation values. Similarity factor is inversely proportional to the average of squared difference between the two profiles, with emphasis on the larger difference among all the time points. When the two profiles are identical, $\mathrm{f} 2=100$. An average difference of $10 \%$ at all measured time point's results in an $\mathrm{f} 2$ value of 50 . The FDA has set a public standard of an $\mathrm{f} 2$ value of 50-100 to indicate similarity of two dissolution profiles.

\section{FT-IR study}

Infrared spectrum was taken (FT-IR, Spectrum RX 1, Perkin Elmer Ltd, Switzerland) by scanning the sample in potassium bromide discs. The samples of pure drug and granules containing different polymers were scanned individually to find the common bands of the vibrational spectra of individual drug and its formulations and also to find the differences in the vibrational spectrum of the formulation.

\section{RESULTS AND DISCUSSION}

The dose of ziprasidone $\mathrm{HCl}$ was 40mg which was determined with the help of the drug profile. The total dose of trihexyphenidyl for a once-daily sustained-release formulation was $4 \mathrm{mg}$, a value which was calculated by equation. Hence, the formulation should release $1 \mathrm{mg}$ in 1 hour like conventional tablets, and $0.25 \mathrm{mg}$ per hour up to 12 hours thereafter. Drug release from planar matrix systems has been investigated theoretically with special emphasis on the influence of a finite dissolution rate on the drug release profile. The mechanism and kinetics of the theoretical drug release of trihexyphenidyl was determined by the application of the Korsmeyer-Peppas model, Higuchi's model, as well as zero order and first order kinetics, as shown in Figure 1. The kinetic studies indicate that drug release depends on swelling, relaxation and erosion of polymer with zero order release kinetics based on correlation coefficient $\left(\mathrm{R}^{2}\right)$ as an indicator of the best fit for the theoretical profile considered. The correlation coefficient $\left(\mathrm{R}^{2}\right)$ was $0.9999,0.7971,0.9694$ and 0.9724 for zero-order, first-order, Higuchi and Korsmeyer-Peppas release models, respectively.

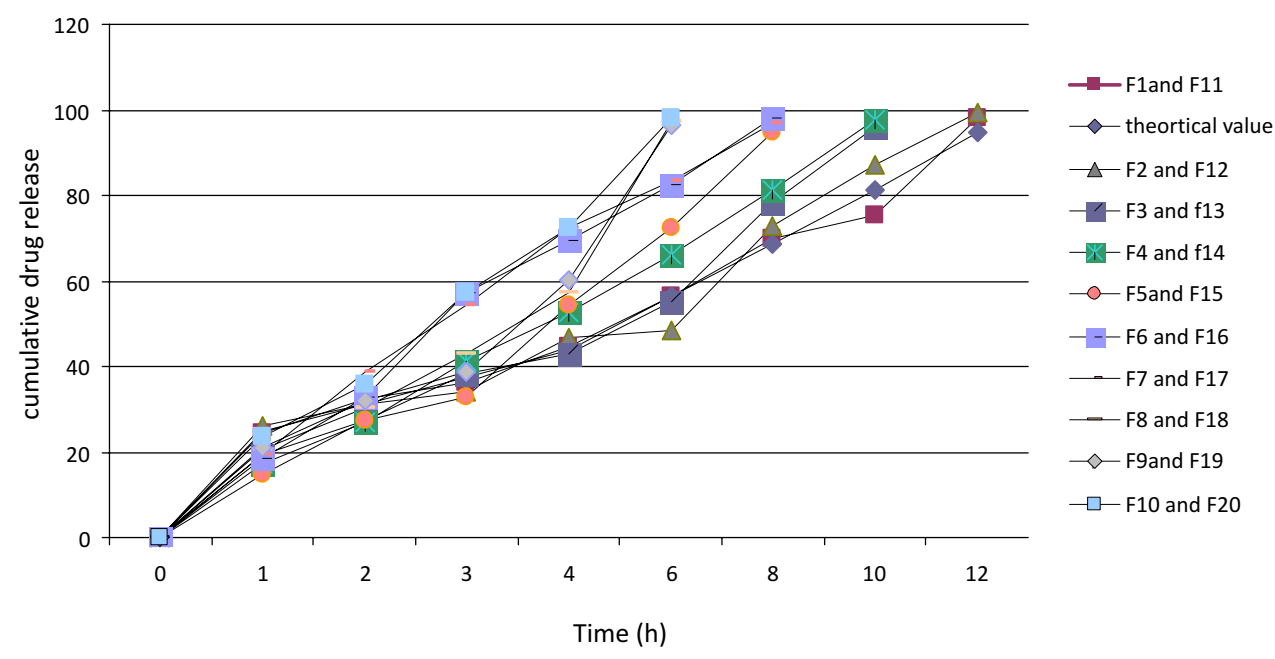

FIGURE 1 - Dissolution profile for Trihexyphenidyl HCl SR in $\mathrm{HCl} 0.1 \mathrm{~N}$ (each data point represents the mean of 3 units). 
In drug excipient physical characteristic studies, the samples which were kept at room temperature, withdrawn and evaluated for physical characteristics like color change at different time intervals (days). Hence, it can be concluded that all the compositions were compatible.

The preformulation studies of $\mathrm{Z} 1$ to $\mathrm{Z} 2$ and $\mathrm{T} 1$ to T10 were evaluated for various physical properties individually, and values given in Table III. Blend was evaluated for bulk density, tapped density, compressibility index, Hausner ratio and angle of repose. From the results shown in Table III, the values of bulk densities for the granules of various formulations indicate good packing characteristics. The compressibility index (CI) for all the formulations was found to be below $15.25 \%$, indicating desirable flow properties. The flow properties of granules were further analyzed by determining the angle of repose for all granules where ranges were less than $30^{\circ}$. The Hausner ratio for all the granules formulated was less than $1.5 \%$.

All the batches (F1 to F20) of tablets were produced under similar conditions to avoid influence of processing variables. The tablets of different formulations were subjected to various evaluation tests, such as thickness, diameter, uniformity of weight, drug content, hardness, friability, buoyancy test and in vitro dissolution. Physical evaluation results of all the formulations are shown in Table IV. In a weight variation test, mass values of the bilayer tablets were between 148.6 and $152.6 \mathrm{mg}$. The average percentage deviation of all tablet formulations was found to be within the limit, and hence all formula- tions passed the test for uniformity of weight as per official requirements. The hardness of tablets was between 6.16 and $8.33 \mathrm{kp}$ and Thickness was 2.5 to $2.76 \mathrm{~mm}$. Hardness and thickness studies indicated the strength of tablets. The percentage friability of all the formulations was between 0.45 and $0.93 \%$. Conventional compressed tablets that lose less than $1 \%$ of their weight are generally considered acceptable. In the present study, the percentage friability for all the formulations was below $1 \%$, indicating that their friability was within the prescribed limits. Values of the hardness test and percent friability indicate good handling properties of the prepared bilayer tablets. On the buoyancy test, floating lag time of all batches was below 30 seconds regardless of viscosity and content of HPMC because of evolution of $\mathrm{CO}_{2}$ resulting from the interaction between sodium bi carbonate and dissolution medium; entrapment of gas inside the hydrated polymeric matrices enables the dosage form to float by lowering the density of the matrices. Total floating time for the HPMC formulations was below $14 \mathrm{hrs}$. The drug content uniformity in the bilayer matrix tablets ranged from 97.39 to $99.94 \%$ for ziprasidone hydrochloride and 98.54 to $101.39 \%$ for trihexyphenidyl hydrochloride.

From the release profiles it was clear that most of the drug of trihexyphenidyl. $\mathrm{HCl}$ was released in $0.1 \mathrm{~N}$ $\mathrm{HCl}$. Approximately $50 \%$ of the drug was released within 5 to $6.2 \mathrm{~h}$ for F1, F2, F3, F11, F12 and F13, but for F4, F5, F8, F9, F10, F14, F15, F18, F19 and F20 release was within 3 to $4 \mathrm{~h}$; for F6, F7, F16 and F17 within 2 to 2.9 h. Similarly, $90 \%$ of the drug release was observed in 10 to $12 \mathrm{~h}$ for F1, F2, F11 and F12; for F3, F4, F13 and

TABLE III - Characterisation of granules

\begin{tabular}{lcccccc}
\hline S.No & Formulation & Bulk density $\mathrm{g} / \mathrm{cm}^{3}$ & Tap density $\mathrm{g} / \mathrm{cm}^{3}$ & Hausner ratio & Compressibility Index $(\%)$ & Angle of repose $\left({ }^{0}\right)$ \\
\hline 1 & $\mathrm{Z} 1$ & $0.453 \pm 0.012$ & $0.51 \pm 0.024$ & $1.116 \pm 0.057$ & $11.02 \pm 3.52$ & $28.31 \pm 1.429$ \\
2 & $\mathrm{Z} 2$ & $0.448 \pm 0.016$ & $0.518 \pm 0.02$ & $1.124 \pm 0.045$ & $13.09 \pm 1.34$ & $27.95 \pm 1.072$ \\
3 & $\mathrm{~T} 1$ & $0.46 \pm 0.02$ & $0.515 \pm 0.007$ & $1.115 \pm 0.02$ & $14.4 \pm 1.27$ & $28.25 \pm 2.47$ \\
4 & $\mathrm{~T} 2$ & $0.46 \pm 0.0$ & $0.54 \pm 0.028$ & $1.095 \pm 0.04$ & $12 \pm 0.7$ & $27.45 \pm 0.07$ \\
5 & $\mathrm{~T} 3$ & $0.445 \pm 0.03$ & $0.52 \pm 0.014$ & $1.105 \pm 0.03$ & $10 \pm 3.11$ & $29.3 \pm 0.98$ \\
6 & $\mathrm{~T} 4$ & $0.45 \pm 0.01$ & $0.52 \pm 0.014$ & $1.1 \pm 0.0$ & $12.45 \pm 3.74$ & $27.75 \pm 1.48$ \\
7 & $\mathrm{~T} 5$ & $0.45 \pm 0.0$ & $0.49 \pm 0.014$ & $1.085 \pm 0.03$ & $10.85 \pm 1.2$ & $29.8 \pm 0.28$ \\
8 & $\mathrm{~T} 6$ & $0.455 \pm 0.02$ & $0.53 \pm 0.028$ & $1.15 \pm 0.0$ & $14.1 \pm 0.56$ & $27.1 \pm 1.69$ \\
9 & $\mathrm{~T} 7$ & $0.45 \pm 0.01$ & $0.51 \pm 0.014$ & $1.13 \pm 0.0$ & $11.75 \pm 0.35$ & $27.95 \pm 1.62$ \\
10 & $\mathrm{~T} 8$ & $0.45 \pm 0.01$ & $0.495 \pm 0.035$ & $1.065 \pm 0.09$ & $8.9 \pm 3.67$ & $26.95 \pm 0.35$ \\
11 & $\mathrm{~T} 9$ & $0.45 \pm 0.01$ & $0.5 \pm 0.028$ & $1.11 \pm 0.02$ & $9.9 \pm 2.26$ & $29.35 \pm 0.91$ \\
10 & $\mathrm{~T} 10$ & $0.44 \pm 0.0$ & $0.52 \pm 0.028$ & $1.125 \pm 0.007$ & $15.25 \pm 4.59$ & $28.7 \pm 0.56$ \\
\hline
\end{tabular}

Z- Ziprasidone.HCl; T - Trihexyphenidyl.HCl Formulation, $\mathrm{n}=3$, mean \pm standard deviation 
TABLE IV - Evaluation study for bilayer tablet formulation

\begin{tabular}{lcccccc}
\hline Formulation & $\begin{array}{c}\text { Thick ness } \\
(\mathrm{mm}) \mathrm{n}=10\end{array}$ & $\begin{array}{c}\text { Buoyancy test }(\mathrm{n}=3) \\
\text { Lag time }(\mathrm{sec})\end{array}$ & $\begin{array}{c}\text { Total floating time }(\mathrm{h}) \\
(\mathrm{kp}) \mathrm{n}=6\end{array}$ & $\begin{array}{c}\text { Friability } \\
(\%) \mathrm{n}=10\end{array}$ & $\begin{array}{c}\text { Deviation in weight } \\
\text { variation }(\mathrm{mg}) \mathrm{n}=20\end{array}$ \\
\hline F1 & $2.6 \pm 0.1$ & $30.33 \pm 0.58$ & $12.33 \pm 0.58$ & $7.56 \pm 0.25$ & $0.85 \pm 0.02$ & $151.4 \pm 3.37$ \\
F2 & $2.63 \pm 0.05$ & $23.33 \pm 0.58$ & $13.33 \pm 0.58$ & $\mathbf{6 . 1 6} \pm \mathbf{0 . 2 3}$ & $0.85 \pm 0.01$ & $152.2 \pm 3.30$ \\
F3 & $\mathbf{2 . 7 6} \pm 0.11$ & $16.33 \pm 0.58$ & $13.33 \pm 1.15$ & $6.5 \pm 0.34$ & $0.72 \pm 0.02$ & $149.5 \pm 4.59$ \\
F4 & $2.73 \pm 0.15$ & $15.33 \pm 2.31$ & $11.33 \pm 1.15$ & $6.6 \pm 0.3$ & $0.66 \pm 0.02$ & $151.2 \pm 3.57$ \\
F5 & $2.5 \pm 0.1$ & $10.00 \pm 1.73$ & $11.33 \pm 1.15$ & $6.7 \pm 0.1$ & $0.94 \pm 0.02$ & $150.1 \pm 4.06$ \\
F6 & $2.7 \pm 0.2$ & $26.00 \pm 3.46$ & $11.33 \pm 1.15$ & $7.96 \pm 0.32$ & $0.93 \pm 0.04$ & $148.9 \pm 4.29$ \\
F7 & $2.75 \pm 0.05$ & $24.67 \pm 1.15$ & $12.57 \pm 0.58$ & $6.93 \pm 0.51$ & $0.67 \pm 0.01$ & $150.6 \pm 4.30$ \\
F8 & $2.74 \pm 1.34$ & $14.33 \pm 2.89$ & $13.00 \pm 1.73$ & $8.33 \pm 0.20$ & $0.93 \pm 0.04$ & $150.3 \pm 4.46$ \\
F9 & $2.64 \pm 0.08$ & $14.67 \pm 0.58$ & $12.33 \pm 1.15$ & $7.73 \pm 0.32$ & $0.67 \pm 0.03$ & $149.8 \pm 4.77$ \\
F10 & $2.67 \pm 0.06$ & $14.00 \pm 1.73$ & $12.00 \pm 0.00$ & $7.46 \pm 0.18$ & $0.94 \pm 0.04$ & $150.2 \pm 4.18$ \\
F11 & $2.68 \pm 0.03$ & $29.33 \pm 0.58$ & $10.33 \pm 0.58$ & $6.6 \pm 0.3$ & $0.67 \pm 0.03$ & $152.6 \pm 2.26$ \\
F12 & $2.76 \pm 0.11$ & $22.33 \pm 1.15$ & $12.33 \pm 1.15$ & $7.7 \pm 0.14$ & $0.90 \pm 0.01$ & $148.6 \pm 4.11$ \\
F13 & $2.5 \pm 0.1$ & $15.67 \pm 1.15$ & $12.57 \pm 0.58$ & $6.76 \pm 0.41$ & $0.90 \pm 0.01$ & $150.8 \pm 4.48$ \\
F14 & $2.66 \pm 0.06$ & $9.67 \pm 0.58$ & $13.33 \pm 0.58$ & $7.4 \pm 0.43$ & $0.46 \pm 0.01$ & $150.4 \pm 3.64$ \\
F15 & $2.71 \pm 0.062$ & $26.33 \pm 0.58$ & $9.57 \pm 0.58$ & $7.1 \pm 0.40$ & $0.92 \pm 0.02$ & $150.7 \pm 2.86$ \\
F16 & $2.67 \pm 0.137$ & $27.00 \pm 3.46$ & $11.57 \pm 0.58$ & $6.63 \pm 0.54$ & $0.92 \pm 0.04$ & $149.6 \pm 3.29$ \\
F17 & $2.65 \pm 0.04$ & $15.67 \pm 0.58$ & $13.57 \pm 1.15$ & $6.16 \pm 0.28$ & $0.73 \pm 0.01$ & $150.6 \pm 3.24$ \\
F18 & $2.6 \pm 0.082$ & $12.33 \pm 0.58$ & $13.57 \pm 1.15$ & $\mathbf{8 . 3 3} \pm \mathbf{0 . 2 0}$ & $\mathbf{0 . 4 4} \pm \mathbf{0 . 0 2}$ & $150.8 \pm 4.12$ \\
F19 & $2.68 \pm 0.02$ & $24.33 \pm 0.58$ & $13.33 \pm 0.58$ & $6.5 \pm 0.34$ & $\mathbf{0 . 9 5} \pm \mathbf{0 . 0 3}$ & $151.6 \pm 4.16$ \\
F20 & $2.64 \pm 0.08$ & $10.33 \pm 0.58$ & $10.57 \pm 1.15$ & $7.7 \pm 0.14$ & $0.65 \pm 0.02$ & $\mathbf{1 4 8 . 5} \pm \mathbf{3 . 2 6}$ \\
\hline
\end{tabular}

mean \pm standard deviation

F14, within 8 to 10 h; for F5, F6, F7, F15, F16 and F17, within 6 to 8 h; and for F8, F9, F10, F18, F19 and F20, within 4 to $6 \mathrm{~h}$. Thus the concentration of the polymers HPMC K4M and HPMC K15M was the predominant controlling factor. Formulations F6 to F10 and F16 to F20 released the drug completely within $8 \mathrm{~h}$. This was ascertained due to the HPMC K4M polymer forming a rigid gel barrier around the tablet ultimately leading to loss of matrix integrity. Increasing HPMC K15M polymer level resulted in sustaining the release for up to 11-12hrs. Table V and Figure 1 show the cumulative percentage release studies for trihexyphenidyl.HCl SR. Based on the results of cumulative drug release profile, it was concluded that F1, F2, F11 and F12 were optimized formulations in which both $\mathrm{F} 1$ and $\mathrm{F} 11$ have $\mathrm{T} 1$ formula and both F2 and F12 have T2 formula. The description of dissolution profiles has been attempted using different release models. Most of the tablet formulation follows zero order release as $r^{2}$ values are between 0.933 and 0.991 . The correlation coefficient $\left(\mathrm{R}^{2}\right)$ was used as an indicator of the best fit for each of the models considered. The mechanisms of drug release are non-Fickian diffusion, since they fitted well with Korsmeyer-Peppas models as their $\mathrm{r}^{2}$ values were in the range 0.922-0.994 with $n$ values above 0.5 . This indicates that drug release depends on swelling, relaxation and erosion of polymer with zero order release kinetics. Table VI depicts the data for the correlation co-efficient for all kinetic models of all formulations. Similarity factor was calculated between selected formulations with a theoretical profile value of trihexyphenidyl $\mathrm{HCl}$. Similarity factor value for F1 and F11 was 77.9; for F2 and F12 67.2. From this value, it was found that formulations F1 and F11 had a release profile similar to that of the theoretical release profile of trihexyphenidyl.HCl SR. Similarity factor value was found to be above 50 and the formulation showed polymer concentration dependent retardation.

Based on the release profiles it was clear that most of the ziprasidone. $\mathrm{HCl}$ was released in $7.4 \mathrm{pH}$ phosphate buffer with $1 \%$ SLS. About $50 \%$ of the drug was released within 50 to $55 \mathrm{~min}$ for F1 to F10 and for F11 to F20 within 55 to $60 \mathrm{~min}$. Similarly, $90 \%$ of the drug release was observed in 105 to $120 \mathrm{~min}$ for F1 to F10 and for F11 to F20 within 120 to $150 \mathrm{~min}$. Among these formulations 
TABLE V - Data for cumulative \% release study for trihexyphenidyl.HCl SR

\begin{tabular}{cccccccccccc}
\hline $\begin{array}{c}\text { Time } \\
\text { (hr) }\end{array}$ & $\begin{array}{c}\text { Theoretical } \\
\text { value }\end{array}$ & F1 \& F11 & F2 \& F12 & F3 \& F13 & F4 \& F14 & F5 \& F15 & F6 \& F16 & F7 \& F17 & F8 \& F18 & F9 \& F19 & F10 \& F20 \\
\hline 0 & 0 & 0 & 0 & 0 & 0 & 0 & 0 & 0 & 0 & 0 & 0 \\
1 & 25 & $24.26 \pm$ & $26.26 \pm$ & $19.2 \pm$ & $17.2 \pm$ & $14.8 \pm$ & $18.5 \pm$ & $19.4 \pm$ & $20.6 \pm$ & $20.9 \pm$ & $23.7 \pm$ \\
& & 0.96 & 0.96 & 0.91 & 0.93 & 0.74 & 0.52 & 0.43 & 0.70 & 1.08 & 0.7 \\
2 & 31.25 & $32.45 \pm$ & $31.25 \pm$ & $27.2 \pm$ & $26.8 \pm$ & $27.5 \pm$ & $32.8 \pm$ & $38.9 \pm$ & $30.2 \pm$ & $32.2 \pm$ & $35.9 \pm$ \\
& & 0.65 & 0.40 & 1.23 & 0.78 & 1.05 & 0.85 & 1 & 0.95 & 0.95 & 1 \\
3 & 37.5 & $36.25 \pm$ & $34.25 \pm$ & $38.11 \pm$ & $41.1 \pm$ & $32.8 \pm$ & $57.2 \pm$ & $54.2 \pm$ & $42.8 \pm$ & $38.9 \pm$ & $57.2 \pm$ \\
& & 0.22 & 0.93 & 0.57 & 0.94 & 1.05 & 0.69 & 0.51 & 0.90 & 1.05 & 0.3 \\
4 & 43.75 & $44.76 \pm$ & $46.75 \pm$ & $43.11 \pm$ & $52.6 \pm$ & $54.2 \pm$ & $69.4 \pm$ & $72.4 \pm$ & $57.2 \pm$ & $60.2 \pm$ & $72.4 \pm$ \\
& & 0.22 & 1.01 & 0.53 & 0.23 & 0.95 & 0.62 & 0.78 & 0.95 & 0.78 & 1.15 \\
6 & 56.25 & $56.24 \pm$ & $48.27 \pm$ & $55.21 \pm$ & $66.2 \pm$ & $72.4 \pm$ & $82.6 \pm$ & $83.5 \pm$ & $97.2 \pm$ & $96.6 \pm$ & $98.1 \pm$ \\
& & 0.07 & 1.56 & 0.78 & 0.83 & 0.78 & 0.62 & 0.87 & 1 & 1.24 & 0.95 \\
8 & 68.75 & $69.72 \pm$ & $72.71 \pm$ & $78.52 \pm$ & $81.2 \pm$ & $94.6 \pm$ & $98.1 \pm$ & $96.7 \pm$ & & & \\
& & 0.19 & 0.58 & 0.47 & 1.74 & 0.60 & 0.72 & 0.55 & & & \\
10 & 81.25 & $75.24 \pm$ & $87.28 \pm$ & $96.1 \pm$ & $97.5 \pm$ & & & & & & \\
& & 0.12 & 0.28 & 0.73 & 0.65 & & & & & & \\
12 & 94.86 & $98.26 \pm$ & $99.26 \pm$ & & & & & & & \\
& & 0.22 & 0.72 & & & & & & &
\end{tabular}

TABLE VI - Data for correlation coefficient for all formulations

\begin{tabular}{lccccc}
\hline \multirow{2}{*}{ Formulation } & \multicolumn{4}{c}{$\mathrm{R}^{2}$} & \multicolumn{2}{c}{ Peppas } \\
& Zero & First & Higuchi & Peppas & (n) \\
\hline F1 \& F11 & 0.971 & 0.797 & 0.969 & $\mathbf{0 . 9 7 2}$ & 0.661 \\
F2 \& F12 & $\mathbf{0 . 9 6 1}$ & 0.749 & 0.959 & 0.922 & 0.656 \\
F3 \& F13 & $\mathbf{0 . 9 8 3}$ & 0.834 & 0.958 & 0.981 & 0.751 \\
F4 \& F14 & 0.978 & 0.856 & 0.993 & $\mathbf{0 . 9 9 4}$ & 0.767 \\
F5 \& F15 & $\mathbf{0 . 9 9 1}$ & 0.892 & 0.971 & 0.985 & 0.842 \\
F6 \& F16 & 0.943 & 0.906 & 0.979 & $\mathbf{0 . 9 8 9}$ & 0.703 \\
F7 \& F17 & 0.933 & 0.951 & $\mathbf{0 . 9 8 1}$ & 0.971 & 0.665 \\
F8 \& F18 & $\mathbf{0 . 9 8 5}$ & 0.806 & 0.921 & 0.963 & 0.733 \\
F9 \& F19 & $\mathbf{0 . 9 8 1}$ & 0.820 & 0.914 & 0.950 & 0.724 \\
F10 \& F20 & $\mathbf{0 . 9 8 8}$ & 0.873 & 0.984 & $\mathbf{0 . 9 8 8}$ & 0.645 \\
\hline
\end{tabular}

F1 to F10 with the Z1 formula showed better dissolution properties than F11 to F20 with the Z2 formula.

Based on the cumulative dissolution studies of trihexyphenidyl. $\mathrm{HCl}$ and ziprasidone. $\mathrm{HCl}$, similarity factor and other physical evaluation studies, the F1 formulation where $\mathrm{T} 1$ and $\mathrm{Z} 1$ were present exhibited good properties of bilayer tablet formulation in terms of excipient proportion. The F1 formulation was therefore selected for the further studies.

The FT-IR spectrum of the bilayer tablet ziprasidone. $\mathrm{HCl}$, trihexyphenidyl. $\mathrm{HCl}$ and $\mathrm{F} 1$ formulation are shown in Figures 2, 3 and 4, respectively. For ziprasido-
ne.HCl, FTIR Spectra wave numbers were $3357 \mathrm{~cm}^{-1}$ (for $\mathrm{NH}$ stretching), $3196 \mathrm{~cm}^{-1}$ (for Aromatic C-H stretch), $2930 \mathrm{~cm}^{-1}$ (for $\mathrm{C}-\mathrm{H}$ stretch), $1714 \mathrm{~cm}^{-1}$ (for $\mathrm{C}=\mathrm{O}$ stretch), $1631 \mathrm{~cm}^{-1}$ (for $\mathrm{C}=\mathrm{N}$ stretch), $1493 \mathrm{~cm}^{-1}$ (for $\mathrm{C}-\mathrm{H}$ bending), $972 \mathrm{~cm}^{-1}$ (for C-N ), $744 \mathrm{~cm}^{-1}$ (for C-H bending) and 651 $\mathrm{cm}^{-1}$ (for C-H bending). For trihexyphenidyl.HCl, FTIR Spectra wave numbers were $3303 \mathrm{~cm}^{-1}$ (for $\mathrm{OH}$ stretching), $3023 \mathrm{~cm}^{-1}$ (for Aromatic C-H stretch), $2931 \mathrm{~cm}^{-1}$ (for C-H stretch), $1446 \mathrm{~cm}^{-1}$ (for $\mathrm{C}=\mathrm{C}$ stretch), $1394 \mathrm{~cm}^{-1}$ (for $\mathrm{CH} 2$ bending), $936 \mathrm{~cm}^{-1}$ (for $\mathrm{C}-\mathrm{N}$ ) and $700 \mathrm{~cm}^{-1}$ (for $\mathrm{C}-\mathrm{H}$ bending). The wavenumbers of individual drug were compared with F1 (combination of Z1 and T1) formulated product IR spectrum. For the F1 formulation, FTIR Spectra wave numbers were $3303 \mathrm{~cm}^{-1}$ (for NH or $\mathrm{OH}$ stretching), $3199 \mathrm{~cm}^{-1}$ (for Aromatic C-H stretch), $2931 \mathrm{~cm}^{-1}$ (for $\mathrm{C}-\mathrm{H}$ stretch), $1713 \mathrm{~cm}^{-1}$ (for $\mathrm{C}=\mathrm{O}$ stretch), $1630 \mathrm{~cm}^{-1}$ (for $\mathrm{C}=\mathrm{N}$ stretch), $1493 \mathrm{~cm}^{-1}$ (for $\mathrm{C}-\mathrm{H}$ or $\mathrm{C}=\mathrm{C}), 971 \mathrm{~cm}^{-1}$ (for $\mathrm{C}-\mathrm{N}$ ) and $744 \mathrm{~cm}^{-1}$ (for $\mathrm{C}-\mathrm{H}$ bending). These results revealed that there was no disturbance in the principle peaks of pure drug ziprasidone. $\mathrm{HCl}$ and trihexyphenidyl.HCl. This further confirms the integrity of pure drugs and their compatibility with the excipients.

\section{CONCLUSION}

The present research was carried out to develop a bilayer tablet of trihexyphenidyl hydrochloride and ziprasidone. $\mathrm{HCl}$ using disintegrant Colloidal Silicon dioxide for the normal release layer and both HPMC K4M and 
HPMC K15M for the sustained release layer. Bilayer tablets showed the appropriate release effect to provide the loading dose of the drug, followed by sustained release for $12 \mathrm{~h}$, indicating promising potential of the trihexyphenidyl hydrochloride and ziprasidone hydrochloride bilayer tablet as an alternative to the conventional dosage form.

\section{ACKNOWLEDGEMENT}

The author is thankful to The Management, Nalanda College of Pharmacy, Nalgonda for their valuable support to complete this work successfully.

\section{REFERENCES}

ABRAHAM, M.A.; ASHIRWAIKAR, A. Formulation of multilayered sustained release tablets using insoluble matrix system. Indian J. Pharm. Sci., v.59, p.312-315, 1997.

ANTHONY, M.; OSSETTON. M. D.; BRIAN, W. Clarke's, Analysis of drugs and poisons. London: Pharmaceutical Press, 2006. v.2, p.1673.

LACHMANN, L.; LIBERMAN, H. A.; KANIG, J.L. Theory and practice of industrial pharmacy. 3.ed. Bombay: Varghese Publishing House, 1987. p.297-299.

OWENS, D. G. C. Guide to the extrapyramidal side-effects of antipsychotic drugs. Cambridge: University Press, 1999. p.18-31.
PORTEUS, H. B.; ROSS, D. N. Mental Symptoms in Parkinsonism following benzhexol hydrochloride therapy. Br. Med. J., v.2, p.138-140, 1956.

RX LIST 2009. Ziprasidone. Available at: $<$ http://www.rxlist. com/script/main/hp.asp>. Accessed on: 14 nov. 2009.

SEAN, C. S. Martindale: The complete drug reference. 34.ed. London: Pharmaceutical Press, 2006. p.728.

THOMSON MICRO MEDEX. Healthcare Series: Available at: <http://www.thomsonhc.com/hcs/librarian/ PFDefaultActionId/pdf>, Accessed on: 28 Nov. 2009.

VELASCO, M. V.; FORD, J. L.; ROWE, P.; RAJABI, S. A. R. Influence of drug; Hydroxy propyl methyl cellulose ratio, drug and polymer particle size and compression force on the release of diclofenac sodium from HPMC tablets. $J$. Control. Release, v.57, p.75-85, 1999.

VIJAY, K.; MARJA, D., LA, L.; RENUS, M.; DONG, Y. Preparation characterization and tableting properties of a new cellulose band pharmaceutical aid. Indian J. Pharm. Sci., v.235, p.129-140, 2002.

Received for publication on $19^{\text {th }}$ November 2010 Accepted for publication on 20 $0^{\text {th }}$ May 2011 
